\title{
FUNDAMENTOS PARA LA PREVENCIÓN DE DESIGUALDADES DESDE EL SECTOR JURÍDICO CUBANO EN FUNCIÓN DEL DESARROLLO SOCIAL
}

Resumen: Las desigualdades jurídicosociales generadas por disposiciones normativas del ordenamiento jurídico cubano atentan contra el desarrollo social. En tal sentido, el presente artículo ofrece la fundamentación de una crítica propositiva al vigente enfoque de género de algunas regulaciones del Código Penal, el Código de Familia y la Ley General de la Vivienda desde la perspectiva de la equidad -para que fundamentalmente por su papel en la toma de decisiones- jueces y fiscales en la práctica jurídica, puedan aplicar evolutivamente el Derecho, a tono con el avance científico actual en materia de género. Dentro de los resultados se obtuvo, que existe una estrecha relación entre la triada género-Derecho-desarrollo social, que debe considerarse en el sector jurídico cubano para la máxima realización material y espiritual de hombres y mujeres en el en el ejercicio de sus derechos.

Descriptores: Género; Derecho; desarrollo social.

\begin{abstract}
Legal-social inequalities generated by some normative provisions of the Cuban legal system threaten social development. In this regard, this article offers the basis for a proactive criticism of the current gender approach of some regulations of the Criminal Code, the Family Code and the General Housing Law from the perspective of equity - for which, fundamentally, because of its role in decision-making - judges and prosecutors in legal practice, can apply the law evolutionarily, in line with the current scientific progress on gender issues. Within the results was obtained, that there is a close relationship between the triad gender-Law-
\end{abstract}

\footnotetext{
${ }^{1}$ Licenciado en Derecho y en Historia. Doctor en Ciencias Pedagógicas y Máster en Derecho Constitucional y Administrativo por la Facultad de Derecho de la Universidad de La Habana. Profesor Titular del Departamento de Derecho de la Universidad de Pinar del Río, Cuba. ORCID 0000-0002-5097-8520. alievez@upr.edu.cu.

${ }^{2}$ Licenciado en Derecho. Máster en Desarrollo Social. Profesor Asistente del Departamento de Derecho de la Universidad de Pinar del Río, Cuba. Estudiante de la Maestría en Derecho Constitucional y Administrativo de la Facultad de Derecho de la Universidad de La Habana. ORCID 0000-0002-0214-9744. silva@upr.edu.cu.
} 
social development, which should be considered in the Cuban legal sector for the maximum material and spiritual realization of men and women in the exercise of their rights.

Keywords: Gender, Law; social development.

\section{Introducción}

La comunidad internacional desde finales del siglo pasado hasta la actualidad, aboga e insiste porque hombres y mujeres gocen de igualdad de oportunidades y derechos en todos los ámbitos de la vida diaria. Es una pretensión que se basa además en la necesidad de que el acceso a bienes y servicios, al desarrollo -en sus disímiles esferas- no pertenezca en su mayoría a un sexo específico, sino que abarque a la sociedad en general.

En Cuba por la esencia socialista del modelo que se defiende constituye una prioridad el cumplimiento de la Declaración Universal de los Derechos Humanos aprobada por la Asamblea General de la Organización de Naciones Unidas (ONU), la cual regula en su artículo primero que "todos los seres humanos nacen libres e iguales en dignidad y derechos" (1948, p.2) y en el artículo séptimo que "todos son iguales ante la ley y tienen, sin distinción,
114

derecho a igual protección de la ley. Todos tienen derecho a igual protección contra toda discriminación que infrinja esta Declaración y contra toda provocación a tal discriminación" (1948, p. 2).

De conformidad con los planteamientos anteriormente expuestos, el ordenamiento jurídico cubano es consecuente con ello-en sentido general- desde la vigente Constitución de la República de 1976, heredera de la Constitución de 1940 en la que más de treinta antes según Silva y Pérez (2017a):

(...) se proscribió la discriminación racial por motivo de sexo o color (artículo 20), expresó en materia de Familia la igualdad absoluta para ambos cónyuges una vez contraído el matrimonio, el disfrute a plenitud de la capacidad civil de la mujer casada sin que necesitara de licencia o autorización marital para regir sus bienes, ejercer libremente el comercio, la industria, la profesión, oficio o arte, y disponer del producto de su trabajo (artículo 43). También declaró el trabajo como un derecho inalienable del individuo (artículo 60); reguló que no se establecería diferencia alguna entre las mujeres casadas y las solteras (artículo 68), reconoció el derecho de los trabajadores a la huelga (artículo 71), y manifestó que son electores todos los cubanos, de uno u otro sexo, mayores de 20 años (artículos 97 y 99). (p.5) 
La actual Constitución cubana hace referencia en el "Capítulo VI Igualdad, a que todos los ciudadanos gozan de iguales derechos y están sujetos a iguales deberes, asimismo, que la mujer y el hombre gozan de iguales derechos en lo económico, político, cultural, social y familiar" (Silva $\&$ Pérez, 2017a, p.2). De la misma se derivan el resto de las normas sustantivas que en el orden social ofrecen al ser humano la posibilidad de hacer cumplir sus derechos.

A pesar de las garantías mencionadas y aun conociéndose el buen ánimo de quienes legislaron el Código de Familia (1975), el Código Penal (1987) y la Ley General de la Vivienda (1988), en algunas de sus disposiciones normativas encuentran indistintamente el hombre o la mujer brechas de inequidad que favorecen a uno $u$ otro sexos cuando debía existir un tratamiento único e igualitario para ambos que los colocara en una posición favorable para el ejercicio de sus intereses o derechos materiales y morales frente al desarrollo. Dichas regulaciones inciden en la aplicación del Derecho en la práctica jurídica de quienes operan en el sector, dígase principalmente los jueces y también -aunque en menor medida- los fiscales atendiendo al cumplimiento del respeto a lo establecido en ley.
Ante tales normas jurídicas el presente artículo tiene como objetivo: fundamentar la superación del actual enfoque de género de las ramas del Derecho Penal, el Derecho de Familia y el Derecho sobre Bienes desde la perspectiva de la equidad, en la interpretación y aplicación de la ley en la práctica jurídica, de manera que posibilite desarrollo social.

Para ello, teniendo en cuenta la triada género-Derecho-desarrollo social y el empleo de métodos tales como el históricológico, el exegético-analítico y la revisión documental, se ofrecen consideraciones teóricas sobre la categoría género, la teoría feminista contemporánea y la equidad como respuesta a las desigualdades, así como la relación entre género y desarrollo. Específicamente en el Código Penal se analizan los delitos contra el normal desarrollo de las relaciones sexuales: la equidad de género en la regulación de cada figura delictiva desde este título, a partir del tratamiento que se le ofrece a cada sexo en la disposición normativa y el marco sancionador para cada sexo en dependencia de la conducta típica. En el Código de Familia en la guarda y cuidado de los hijos disuelto el vínculo matrimonial: la equidad de género en la regulación de la disposición normativa, y el tratamiento que se le ofrece a cada sexo estando en igualdad de 
condiciones. En la Ley General de la Vivienda, en los derechos y obligaciones de los propietarios de viviendas: la equidad de género en la regulación de la disposición normativa, y el tratamiento que se le ofrece a cada sexo en el caso de poseer la condición de propietario de la vivienda.

\section{Reflexiones sobre género, la teoría} feminista contemporánea y la equidad como respuesta a las desigualdades

En los estudios científicos según Vasallo (2004) la categoría género es de nueva introducción. Según Pautassi (citado en Silva González, Pérez Véliz \& Páez Cuba, 2017):

(...) empezó a ser utilizada en las Ciencias Sociales en la década de los setenta en los países del primer mundo (Estados Unidos y Europa), extendiéndose más tarde a América Latina y el Caribe, África y Asia; pero se reconoce su origen en la obra del sicólogo de Nueva Zelandia, Jhon Money, quien en 1951, usa el concepto gender por primera vez para referirse a un componente cultural, fundamentalmente a la influencia educativa, en la formación de la identidad sexual. (p. 5)

Para autores como Scott (1990); Fleitas (2000); Miranda y Peña (2001); Valdebenito (2002); Fernández et al. (2003); Proveyer (2005); Lagarde (2008); y Caram (2016) el género es una construcción social que se basa en diferencias biológicas. Dicho planteamiento, se vislumbraba en la V Conferencia Internacional de la Mujer celebrada China (1995), que acordó que la palabra género se diferencia de sexo para expresar que el rol y la condición de hombres y mujeres responden a una construcción social y están sujetos a cambios.

Atendiendo a las consideraciones anteriores se piensa que desde la década de los años 90del pasado siglo, existe consenso en la doctrina, en torno a una definición de género similar $y$ se asume en la investigación al género según Silva, Pérez y Páez (2017) como “aquel proceso de construcción social y/o cultural que asigna a cada persona según su sexo -desde el momento de su nacimiento-, características, roles, valores y normas de todo tipo, ya sean sociales, políticas, económicas, jurídicas, culturales y psicológicas"(p.7).

Asimismo, se considera que sexo y género no significan lo mismo, en tanto el primero se refiere a las condiciones anátomo-fisiológicas del ser humano (Miranda \& Peña, 2001; Proveyer, 2005).

Al introducir el tema de género en la teoría feminista desde la Sociología, un referente necesario por su significación, es la obra "Contemporary Sociological Theory" de George Ritzer (1992), 
reproducida en Cuba con el título Teoría Sociológica Contemporánea, primera y segunda parte, por la Editorial Félix Varela de La Habana en el año 2008. A tenor de la investigación se utilizaron las consideraciones expuestas en el capítulo 8 de dicha obra sobre la teoría feminista contemporánea de Patricia Madoo Lengermann y Jill Niebrugge-Brantley, las cuales Ritzer tuvo en cuenta.

Para Madoo y Niebrugge-Brantley (2008a), "las cuestiones feministas han logrado introducirse directamente en el discurso académico y universitario de la sociología profesional” (p.366), y se ha utilizado una parte de la teoría sociológica para lo que se ha denominado dentro de la disciplina: la sociología del género (estudio de los roles y las identidades del hombre y la mujer, y las relaciones entre los hombres y las mujeres).

Plantean que el término género suele emplearse generalmente en la Sociología para hacer alusión a las mujeres: lo que constituye el enfoque principal del feminismo que se centra en la perspectiva humana de las mujeres.

Relacionado con lo anteriormente expuesto, es preciso abordar -para comprender el alcance y la posición que se adopta en la investigación sobre el enfoque de género en el ordenamiento jurídico cubano desde la perspectiva de la equidad-, las variedades de la teoría feminista contemporánea, cuyo contenido expresa la teoría de la diferencia, la teoría de la desigualdad y la teoría de la opresión de género.

En este caso se enfatiza en la teoría de la desigualdad por la importancia que tiene la equidad de género en el estudio, al analizarse como respuesta a las desigualdades existentes en la sociedad actual, es decir, a las brechas entre hombres y mujeres en la concepción de desarrollo y que no están ajenas -en sentido amplio- a algunas normas jurídicas cubanas.

Madoo y Niebrugge-Brantley (2008b), analizan dichas teorías respondiendo a dos preguntas básicas: ¿qué hay de las mujeres? y ¿por qué la situación es como es? En tal sentido refieren que, para la primera interrogante, la respuesta está esencialmente en que la localización y experiencia de las mujeres, que en la mayoría de los casos difiere con relación a los hombres en las mismas condiciones, es menos privilegiada y está expuesta atendiendo a las relaciones de poder, a la opresión y la subordinación.

La teoría de la diferencia plantea que la situación es como es (contestación a la pregunta 2) debido a explicaciones biosociales, institucionales y psico- 
sociológicas. En el caso de la teoría de la desigualdad se refiere a explicaciones liberales de la desigualdad, a explicaciones marxistas, de Marx y Engels y marxistas contemporáneas. En el caso de la tercera teoría de la opresión responde a explicaciones psicoanalíticas, radicalfeministas, sociales feministas y feministas de la opresión de la tercera ola.

Específicamente las teorías de la desigualdad se caracterizan por cuatro ideas esenciales que son básicas para el estudio (Madoo \& Niebrugge-Brantley, 2008a).

a) Los hombres y las mujeres no solo están situados en la sociedad de manera diferente, sino también desigual (las mujeres tienen menos recursos materiales, status social, poder y oportunidades para la autorrealización que los hombres en la misma condición).

b) La desigualdad procede de la misma organización de la sociedad, no de ninguna diferencia biológica o de personalidad entre los hombres y mujeres.

c) El ser humano puede variar según su perfil de capacidades y rasgos, ningún modelo de variación natural relevante distingue a los sexos (afirmar que existe desigualdad entre los géneros, equivale a decir que las mujeres tienen situacionalmente menos capacidad que los hombres para percatarse de la necesidad de autorrealización que comparten con los hombres).

d) Tanto los hombres como las mujeres responderán mejor ante estructuras y situaciones sociales más igualitarias (mantiene que es posible cambiar la situación).

Al decir de Madoo y Niebrugge-Brantley (2008b), el feminismo liberal y el feminismo marxista, intentan explicar las desigualdades entre hombres y mujeres.

El feminismo liberal parte de la identificación de la división sexual del trabajo, de la existencia de dos esferas separadas de actividad social: la pública y la privada; de la localización primaria de los hombres en la primera esfera, y de las mujeres en la segunda, y de la socialización sistemática de los niños para que desempeñen papeles y vivan en esferas apropiadas a su género.

El feminismo marxista, en cambio, encuentra sustento en las concepciones de Marx y Engels sobre la teoría de la opresión de clase, que se centra en la dominación de los trabajadores en interés de la clase dominante, y en la enorme fuerza de la dominación, la opresión y el conflicto de clases en la estructuración de las relaciones internacionales e intranacionales. Combina el análisis marxista de clase y la teoría 
feminista. Según Madoo y NiebruggeBrantley (2008b):

$\mathrm{Su}$ análisis más famoso respecto a esta cuestión se encuentra en Los orígenes de la familia, la propiedad privada y el Estado, escrita y publicada en 1884 por Engels, quien utilizó para ello extensos escritos que realizó Marx pocos años antes de su muerte, en 1883 (p. 554).

Las bases de la teoría del feminismo marxista Madoo y Niebrugge-Brantley (2008a), son las siguientes:

- La subordinación de las mujeres no es resultado de su constitución biológica, sino de un orden social que tiene raíces históricas.

- El fundamento de la subordinación de las mujeres reside en la familia.

- La sociedad legitima a la familia como la institución central o fundamental de todas las sociedades.

- Los factores económicos contribuyeron a la derrota históricomundial del sexo femenino (los hombres se proclamaron propietarios de los recursos esenciales de la producción económica lo que les confirió poder económico y las mujeres servían como medio para transmitir y preservar la propiedad).

- Las estructuras de dominación asociadas al trabajo crearon un orden político para salvaguardar los sistemas de
119

dominación que junto a la familia y las transformaciones de los sistemas económicos, enmarcó la dependencia y subordinación de las mujeres.

Según Varela (2013), Engels señaló que el origen de la sujeción de las mujeres no está precisamente en causas biológicas, la capacidad reproductora o la constitución física, sino sociales. En concreto, en la aparición de la propiedad privada y la exclusión de las mujeres de la esfera de la producción social. Según este análisis, la emancipación de las mujeres está ligada a su independencia económica.

En el feminismo, para Lagunas, Beltrán y Ortega (2016), la “radicalidad de género se encuentra en la certeza inclusiva de mujeres y hombres, en relaciones basadas en la equidad, la igualdad de oportunidades y la democracia” (p. 63).

Al analizar las teorías feministas contemporáneas, donde a partir de su objeto de estudio las mujeres constituyen el centro de ellas, se evidencia cómo las diferencias y/o desigualdades que existen hoy con respecto al hombre, tienen un carácter histórico y se manifiestan desde el auge de las relaciones económicas en diferentes ámbitos y esferas como la social, la política, la económica y la personal.

A estas, se pudiera agregar que la esfera jurídica no está exenta si se entiende que el 
Derecho como expresión de la clase dominante $\mathrm{o}$ en el poder, aunque tenga como principio la igualdad y el ideal de justicia, se basa o construye por el pensamiento o las concepciones del ser humano que tiene incorporado desde su nacimiento -con independencia de sus funciones biológicas-, una mentalidad que prepondera al hombre y subordina a la mujer por determinados roles sociales, características y potencialidades. La teoría de la desigualdad entre los géneros explica o fundamenta el proceso que por herencia han recibido las mujeres.

La exposición, grosso modo, de dichas teorías se utilizan como base para el análisis de la teoría del enfoque de género y posteriormente de la equidad, a tener en cuenta en el presente estudio. Constituyen el punto de partida para comprender el porqué de la necesidad de desarrollar estudios y aplicar alternativas que tengan por objetivo la posición de un sexo frente a otro como guía para enfrentar la desigualdad y crear estrategias para erradicarlas, llevar a cabo el análisis del enfoque de género.

Normalmente, se asume que las diferencias entre hombres y mujeres se deben a los determinantes biológicos, al sexo; sin embargo, la psicosociología ha demostrado que estas diferencias, que se extienden desde los más simples aspectos síquicos hasta los más complejos, se deben a la multitud de factores de tipo sociocultural, además de los biológicos; pues para la Psicología, la Sociología y la Antropología los términos hombre y mujer -además de su connotación biológica-, tienen una enorme connotación social (Andrés-Pueyo,1996).

"Los estudios de la mujer enfocados desde la Sociología a escala internacional se han caracterizado por ser androcéntricos, donde lo masculino es tomado como punto de referencia para los estudios de naturaleza social, por encima de lo femenino" (Maceo, 2012, p. 5).

Según la menciona autora, una de las causas de tal hecho, es haber sido fundada por hombres en una etapa en que las condiciones económicas determinaban la manera de ser de hombres y mujeres; estas últimas sometidas tanto por el régimen económico como por los valores, la moral y los prejuicios que beneficiaban al hombre y a ella la sometían a los marcos del hogar y estrictamente a la actividad reproductiva.

Entre los estudios de los clásicos dentro de la Sociología que involucran a la mujer se pueden encontrar los relacionados con la familia como centro de atención, tal es el caso de E. Durkheim, Talcott Parson y Max Weber. Los enfoques de estos autores se 
pueden considerar como primera tendencia sobre estudios de sociología del género. Caracterizado por el discurso androcéntrico que pone a la mujer por debajo de las capacidades del hombre excluyéndola del espacio público; atribuyen además a las mujeres una identidad pasiva que las somete a las voluntades del sexo opuesto. (Maceo, 2012, p.5)

$\mathrm{Al}$ analizar los enfoques de género desde la Sociología, se pueden distinguir tres tendencias (López, 2011):

$\checkmark \quad$ La de un discurso androcéntrico que no considera al género como una construcción social y en no pocas ocasiones, al abordar la situación de las mujeres lo hace desde una posición acrítica y tradicional; sin cuestionar la subordinación femenina ante el poder masculino, así como la exclusión de la mujeres de los espacios públicos, atribuyéndoles como su lugar naturalmente asignado el ámbito familiar, sin notar la capacidad de estas para realizar numerosas tareas como entes activos y no desde la pasividad por la que son caracterizadas en este primer acercamiento desde la teoría sociológica.

$\checkmark$ La de un discurso cercano al feminismo, desarrollado por hombres que han visualizado la situación real de subordinación vivida por la mujer en la historia y en el mundo y,

$\checkmark \quad$ La del discurso académico feminista elaborado por mujeres en el presente siglo.

En el caso de la primera, no se cuestiona la subordinación femenina ante lo masculino, ni su exclusión del espacio público, razón por la que atribuye fundamentalmente a las mujeres una identidad pasiva que se construye en el marco de la familia, excluyendo el papel protagónico de la misma.

La segunda tendencia, referida a un discurso cercano al feminismo, desarrollado por hombres que han visualizado la situación real de subordinación vivida por la mujer en la historia y en el mundo moderno, es válido plantear que según López (2011), John Stuart Mill es uno de los primeros pensadores que se opone a la exclusión de las mujeres de la esfera pública, rechazando la idea de que la desigualdad entre los sexos no está determinada por factores biológicos hallando como consecuencias de esta situación las diferencias en el modo de educar a ambos sexos donde solo se capacitan a los hombres para intervenir en la vida pública.

Para Fleitas (2000), a John Stuart Mill, Federico Engels y Carlos Marx:

Se les atribuye el mérito de iniciar, en esta especialidad, una nueva lectura sobre la 
situación social de explotación que vivía la mujer en el siglo XIX. De hecho, el pensamiento feminista actual siempre tiene como punto de referencia -tanto para abrazar como para criticar sus ideas- la obra de estos pensadores (p.3).

Plantea López (2011) que dichos pensadores aportaron miradas novedosas respecto a este tópico al cuestionar la opresión de género como un tipo particular, declarado como burdo, pero sumamente eficaz de explotación, que está intrínsecamente mezclada con la milenaria división sexual del trabajo, como forma de las desigualdades sociales. Ellos reconocieron la importancia de la mujer como sujeto social transformador.

En la tercera tendencia, que se refiere al discurso académico feminista elaborado por mujeres en el presente siglo, se reconocen varias clasificaciones con respecto al feminismo. Dentro de sus características se ubica la naturaleza interdisciplinaria de esta problemática, como se había apuntado. Estas corrientes acentúan la importancia de la dominación ideológica masculina en el análisis de la dominación social, desde un enfoque macrosocial de la desigualdad de los géneros, que crea un sistema de identificaciones de las tareas más importantes y menos importantes.
Esta ideología, plantea la misma autora, rechaza la devaluación que se produce de las actividades reproductivas de las mujeres -en lo doméstico-, a costa de una idealización de otras actividades como la maternidad y una invisibilidad de otras que se realizan en los espacios públicos y que son importantes desde el punto de vista de la producción de bienes y mercancías.

Las feministas radicales insisten en que el patriarcado puede destruirse, si se comienza por la reconstrucción básica de la conciencia de hombres y mujeres, de manera que cada uno de los individuos reconozca su propio valor y fuerza, rechazando efectivamente las presiones ejercidas por los patrones patriarcales socialmente establecidos, que han logrado a lo largo del devenir histórico que las féminas se consideren a sí mismas como seres débiles y extremadamente dependientes de las figuras masculinas, ocupando posiciones secundarias, es necesario entonces establecer lazos cooperativos entre los sexos en aras de su fortalecimiento, sin reparar en sus diferencias, promoviendo la defensa mutua (López, 2011,p. 1).

Consideran los autores de la investigación, que es significativo para cumplir con tal ideal desarrollar y aplicar tanto en los espacios privados como en los 
públicos estudios con enfoque de género. Este último se concibe según Ahr (2007), como los diferentes papeles que la sociedad asigna a mujeres y hombres y que se reflejan, en la división y carga de trabajo, en el diferente acceso a los recursos y el desigual control sobre ellos, así como en las distintas posibilidades que tienen las personas de ejercer influencia política y social.

Debe razonarse además, que para llevar a cabo el análisis del enfoque de género, la finalidad debe estar siempre dirigida a disminuir o erradicar las brechas de desigualdad, o sea, lograr la justicia y la equidad entre hombres y mujeres.

En tal sentido, es preciso acotar que para el Derecho romano, justicia es la palabra de donde proviene el ius (Derecho) y se define como "el arte de lo bueno y lo equitativo" (Celso, s/f, p.11). Para Ulpiano (s/f) era: "la voluntad constante y perpetua de dar a cada uno el derecho que le pertenece" (p.11). Dicha definición de Ulpiano esboza que "la justicia no consistía en un trato igual para todos, sino que por el contrario consistía en dar a cada uno lo que le correspondiera, es decir, afirmaba como justa la desigualdad" (Colectivo de autores, 2006, p.11).

La equidad como una palabra frecuente es considerada entre otras acepciones, por el Diccionario de la Real Academia de la
Lengua Española, edición del tricentenario, y el Diccionario El Mundo.es, como la cualidad que mueve a dar a cada uno lo que merece; justicia, imparcialidad en un trato o un reparto.

En el Derecho romano fue utilizada también para la promulgación de nuevas leyes, para servir de fundamento a normas que dictaban lo pretores y otras para distinguir desde el punto de vista el arbitrio judicial, cuando es posible que el juzgador decida un pleito por razones de equidad y buena fe (Colectivo de autores, 2006). Para Trujillo y Hernández (2008) “equidad es un término que expresa equilibrio, igualdad en las oportunidades, una relación justa" ( $p$. 462).

Según Valdebenito (2002) supone un disfrute de los bienes sociales, recursos, las mismas oportunidades en la toma de decisiones, y trabajar juntos ambos sexos para lograrlo.

Para Maurizio (2010), "la equidad de género es un elemento esencial para alcanzar niveles elevados de desarrollo económico, integración social y para construir sociedades democráticas donde la ciudadanía sea ejercida plenamente” (p. 8).

Dicha equidad como se mencionó, no es sinónimo de igualdad con respecto al género. Para la autora anterior, las responsabilidades y las oportunidades de las 
mujeres y de los hombres no dependen de que hayan nacido mujeres u hombres; es un problema de derechos humanos y una condición previa para la consecución de un desarrollo sostenible centrado en las personas.

Para Miranda y Peña (2001) equidad de género es la distribución justa de acuerdo a los intereses y necesidades de hombres y mujeres, es tener derecho a acceder con justicia e igualdad al uso, control y beneficio de los mismos bienes y servicios de la sociedad, así como a la toma de decisiones en los ámbitos de la vida social, económica, política, cultural y familiar. "Es la aceptación de las diferencias entre hombres y mujeres, y la aceptación también de derechos, buscando el ideal de un equilibrio en el que ninguno de ambos sexos se beneficie de manera injusta en prejuicio del otro" (p. 77).

No alejada de las consideraciones planteadas sobre la equidad, la primera Conferencia Mundial sobre la Mujer, en México (1975) que culminó con la propuesta de un Plan de Acción aprobado por la Asamblea de las Naciones Unidas, acordó quela igualdad es al mismo tiempo un objetivo y un medio por el cual los individuos se benefician del mismo trato en el marco de la ley y de las mismas oportunidades para gozar sus derechos $\mathrm{y}$ desarrollar sus talentos y habilidades de manera que puedan participar en el desarrollo político, económico, social y cultural, tanto como beneficiarios que como agentes activos.

Siguiendo esta línea de pensamiento, desde el punto de vista del Derecho, según Camargo (1991), la perspectiva de género "establece una teoría social que trata de explicar (...) comportamientos sociales de hombres y mujeres en sociedad, (...) destacando la existencia real del género femenino y masculino, sin dominio de uno sobre el otro, sin jerarquías y $\sin$ desigualdades" (p. 29). Para la abogada Staff (1999), significa la promoción de la igualdad y de las nuevas identidades de género, reduciendo o eliminando las causas y efectos de la discriminación en el ámbito jurídico.

Según Valdebenito en el 2002, es “tomar en consideración y prestar atención a las diferencias entre mujeres y hombres en cualquier actividad o ámbito dados en una política" (p.41).

Los investigadores coinciden con Miranda y Peña (2001) y Valdebenito (2002), en que la equidad de género no supone que hombres y mujeres sean iguales, pero sí que tengan acceso y disfruten de los bienes sociales, oportunidades y recursos 
sin distinción alguna, sin que un sexo prevalezca por encima del otro.

A tenor de la investigación se entenderá por enfoque de género en el ordenamiento jurídico cubano desde la perspectiva de la equidad, la posición y el tratamiento que ofrece para hombres y mujeres el conjunto de normas que dan orden estructural y funcional al Derecho, sobre la base de un equilibrio en el que ninguno de ambos sexos se beneficie de manera injusta por encima del otro (Silva, Pérez \& Páez, 2017a, p. 10).

\section{Género y desarrollo: una relación necesaria en el estudio}

La promoción de la igualdad de derechos de las mujeres y las niñas, y la equidad entre las primeras y los hombres, continúa siendo un reto y una necesidad a garantizar desde el punto de vista legislativo a través de las normas, categorías y principios que componen los ordenamientos jurídicos a nivel internacional y nacional, de manera que se encuentren a la par de los adelantos y estudios científicos en torno a la temática de género.

En tal sentido, para las profesoras de Derecho, Sanchis y Suárez (2017): “en las últimas décadas la nación cubana ha logrado ser paradigma social y jurídico de la igualdad de género, promoviendo estrategias dirigidas a enraizar la igualdad entre los miembros de la sociedad" (p. 322).
En el ámbito cubano actual, según un informe reciente de ONU-Cuba con fecha 8 de marzo de 2016 "promover la equidad de género y el empoderamiento de las mujeres es fundamental para acelerar el desarrollo humano sostenible" (p. 1). Desde el año 2000 este es un objetivo primordial para la agenda de trabajo de quienes integran el Programa de las Naciones Unidas para el Desarrollo (PNUD). Dicho informe plantea que el esfuerzo comprende la promoción de la igualdad de derechos de las mujeres y niñas, la lucha contra las prácticas discriminatorias y la impugnación de los roles y estereotipos sexistas que sirven de fundamento a las desigualdades y la exclusión; porque son prácticas culturales que se trasmiten de generación en generación en todas las sociedades y que sobrevaloran lo masculino y el status, conocimientos y experiencias de los hombres.

El término desarrollo etimológicamente, según el Diccionario de la Real Academia de Lengua Española, edición de tricentenario (2014), se refiere a la acción y efecto de desarrollar y esta se define como acrecentar, suceder, progresar, crecer económica, social, cultural o políticamente.

Según Chiarotti (1995) la I Conferencia Mundial sobre la Mujer, en 1975, en México, culminó con la propuesta de un 
Plan de Acción aprobado por la Asamblea de las Naciones Unidas, donde se acordó quedesarrollo significa desarrollo total (político, económico, social, cultural y en las otras dimensiones de la vida humana, así como también desarrollo de los recursos económicos, materiales y crecimiento físico, moral, intelectual y cultural del ser humano). Dentro de él se le prestó importancia a la dimensión moral para asegurar que sea justo y estuviera en correspondencia con las necesidades y los derechos del individuo.

Según Zona Económica (citado en Rodríguez \& Páez, 2016) se considera al desarrollo como la condición de vida de una sociedad en la cual las necesidades auténticas de los grupos y/o individuos se satisfacen mediante la utilización racional, es decir, sostenida, de los recursos y los sistemas naturales. Para ello se utilizarían tecnologías que no se encuentran en contradicción con los elementos culturales de los grupos involucrados.

Es criterio de Rodríguez y Páez (2016) que existen teorías actuales que ofrecen conceptos como desarrollo sostenible, desarrollo local y desarrollo social. El término Desarrollo Sostenible, perdurable o sustentable, plantean, fue formalizado por primera vez en el documento conocido como Informe Brundtland (1987), como resultado de los trabajos de la Comisión Mundial de Medio Ambiente y Desarrollo de las Naciones Unidas, creada por Asamblea General en 1983. En él se define al Desarrollo Sostenible según Molina (2011), como forma de "satisfacer las necesidades de las generaciones presentes sin comprometer las posibilidades de las del futuro para atender sus propias necesidades" (p.16).

Otra de las concepciones de desarrollo actuales, es la de Desarrollo Humano, surgido en el marco del Programa de las Naciones Unidas para el desarrollo (PNUD). En el Primer Informe sobre Desarrollo Humano de 1990 se define como un proceso en el cual se amplían las oportunidades del ser humano, las cuales pueden ser infinitas y cambiar con el tiempo. Sin embargo, a todos los niveles del desarrollo, las tres más esenciales son: disfrutar de una vida prolongada $\mathrm{y}$ saludable, adquirir conocimientos y tener acceso a los recursos necesarios para lograr un nivel de vida decente.

Para la Facultad Latinoamericana de Ciencias Sociales (FLACSO) en Cuba, la concepción de desarrollo se distingue no solo como un proceso económico -aunque lo supone- sino además como profundo y complejo proceso social, cuya meta final es la transformación total de una formación 
social capitalista subdesarrollada, o de la periferia del sistema mundial en una sociedad diametralmente diferente a aquella (Programa de la Maestría en Desarrollo Social, 2015).

De ahí que, por su naturaleza, el
desarrollo sea socialista en su
sentido posible: simultáneamente
promueve la creación y
consolidación de las condiciones
técnico-económicas que
garantizan la satisfacción de las
necesidades materiales y sociales
de la población, según
especificidades yistórico-
concretas, y la formación de
nuevos valores éticos, políticos,
culturales, así como nuevas
actitudes de participación,
cooperación, solidaridad y
comprensión entre los seres
humanos, todo lo cual no se
"desprende" automáticamente del
crecimiento de las fuerzas
productivas (p. 3).

Este desarrollo utiliza la riqueza social de forma tal, que propende un modo de vida cualitativamente diferente sustentado entre otros accesos y derechos sociales, al trabajo; a la prevención y atención médicosanitarias; al cultivo del intelecto y de la subjetividad; a la protección y asistencia sociales durante la etapa productiva de la vida y después de ella; al logro de una calidad de vida tan plena como lo permitan las condiciones del desenvolvimiento material de la sociedad en cada momento histórico-concreto dado.
Es también un desarrollo que promueve las relaciones sociales de tipo locales de mayor o menor amplitud, como agrupaciones humanas en permanente interacción social, que, conviviendo en un área geográfica determinada, con recursos propios y externos, con unidad de propósitos, participan en procesos autogestionarios con el fin de mejorar las condiciones económicas y culturales de la comunidad. Promueve valores como son la igualdad, la justicia y la equidad social, así como la satisfacción de las necesidades básicas de las personas junto a la elevación de la calidad de vida de las mismas.

El área del desarrollo social, según FLACSO (2015) “es esencialmente interdisciplinaria, de ella derivan aspectos teóricos centrales como las políticas sociales y la equidad, entre otros, asimismo implicaciones prácticas, como la transformación social, la participación social, el desarrollo local, y otras más" (p.4).

Se asume en la investigación al desarrollo como el progreso en todas las dimensiones de la vida humana: político, económico, social, cultural, material, moral e intelectual (Conferencia Mundial sobre la Mujer, México, 1975) y se agrega la dimensión jurídica como base esencial para lograrlo en cada una de ellas. Se concibe al 
desarrollo social como el aumento de la calidad de vida del ser humano y la satisfacción de sus necesidades básicas como ser social-, lo que pudiera traducirse en el acceso al trabajo, a la atención médicosanitaria, a la superación intelectual, a la protección y asistencia sociales, a la igualdad, la justicia, la equidad de las leyes que rigen su actuar, así como la posibilidad de autogestionar el progreso económico y cultural de su comunidad.

\section{Análisis del enfoque de género en el} Derecho Penal, el Derecho de Familia y el

\section{Derecho sobre Bienes desde la perspectiva de la equidad}

Según Matilla (citado en Silva, Pérez \& Páez, 2017) “el Derecho Penal es aquella rama del ordenamiento jurídico general caracterizada por el conjunto de normas, conceptos, tesis, juicios, postulados, principios y categorías, relacionadas con la actividad delictiva en una sociedad determinada" (p. 10).

El Código Penal cubano Los tipos penales de Violación, Pederastia con Violencia y Abusos lascivos, tienen, en sus figuras básicas, la siguiente regulación jurídico-penal:

Artículo 298.1: Se sanciona con privación de libertad de cuatro a diez años al que tenga acceso carnal con una mujer sea por vía normal o contra natura, siempre que en el hecho concurra alguna de las circunstancias siguientes:

a) usar el culpable de fuerza o intimidación suficiente para conseguir su propósito;

b) hallarse la víctima en estado de enajenación mental...o carente de la facultad de dirigir su conducta.

Artículo 299.1: El que cometa actos de pederastia activa empleando violencia o intimidación, o aprovechando que la víctima esté privada de razón o de sentido o incapacitada para resistir, es sancionado con privación de libertad de siete a quince años.

Con la regulación de dichos delitos en el Código Penal vigente desde 1987 según Rega (2003), se incorporan actos, agresiones y abusos sexuales que atentan directa o indirectamente contra el normal desenvolvimiento de las relaciones sexuales.

Estas figuras delictivas incluyen tanto la libertad del sujeto de elegir de forma autónoma en el ámbito de la sexualidad lo referente a la excitación y satisfacción sin traspasar las barreras del Derecho Penal, así como de elegir su pareja, determinar la opción sexual que se prefiera en cada momento. 
El enfoque de género a partir de un análisis crítico en ambos delitos y desde la perspectiva de equidad, atendiendo a los sujetos que intervienen $y$ el marco sancionador, permite apreciar que el legislador cubano formuló dos figuras de delitos analógicamente semejantes por presentar conductas similares, pero con diferencias punitivas para ambos sexos (Silva, Pérez \& Páez, 2017, p. 13).

En el caso de la Violación, según la previsión legislativa del artículo, se presenta solo a la mujer como sujeto pasivo del delito, mientras que en la Pederastia con Violencia la acción recae sobre el hombre. En el caso de la sanción, se evidencia en el marco sancionador del delito de Violación de cuatro a diez años, a la mujer, con un tratamiento desventajoso con respecto al marco sancionador del hombre en la Pederastia con Violencia, lo que evidencia o sugiere que el legislador otorgó con la plasmación de tal diferenciación, una mayor protección a la integridad sexual del hombre de siete a quince años, como si fuera de superior valor a la integridad sexual de la mujer de cuatro a diez años.

Según la consideración de los autores, se está en presencia de una concepción expresada en Ley, de carácter tradicionalista y sexista, que no otorga el mismo tratamiento para ambos sexos, aún cuando la propia práctica jurídica y social indica que la Violación tiene mayor incidencia que la Pederastia con Violencia. Se está en definitiva, en presencia de disposiciones normativas que suponen una diferencia de género por ende discriminatoria, que reconoce que en materia penal en Cuba, no se ha logrado superar el tratamiento del contexto del delito de Violación, con cualquier persona, dígase hombre o mujer como sujeto pasivo del delito.

Se considera que dicha problemática hubiera sido resuelta con una única norma que contemplara a ambos sexos como sujetos pasivos de los dos delitos antes mencionados, pudiendo quedar de la siguiente forma:

Artículo 298.1.- Se sanciona con privación de libertad de cuatro a diez años al que tenga acceso carnal con una mujer o un hombre, sea por vía normal o contra natura, siempre que en el hecho concurra alguna de las circunstancias siguientes: a) usar el culpable de fuerza o intimidación suficiente para conseguir su propósito.

b) hallarse la víctima en estado de enajenación mental...o carente de la facultad de dirigir su conducta.

El Código de Familia como norma sustantiva fundamental en materia de Familia, según Rojas (citado en Silva \& 
Pérez, 2012) "marcó un avance importante desde el punto de vista jurídico desde el triunfo de la Revolución, al desagregar las materias familiares del viejo Código Civil español" (p. 37). En lo referente a la guarda y cuidado de los hijos menores al disolverse el vínculo matrimonial. La Sección Segunda "De la Guarda y Cuidado y de la Comunicación entre Padres e Hijos" plantea en su articulado:

Artículo 88.- Respecto a la guarda y cuidado de los hijos, se estará al acuerdo de los padres, cuando estos no vivieren juntos.

Artículo 89.- De no mediar acuerdo de los padres o de no ser el mismo atentatorio a los intereses materiales o morales de los hijos, la cuestión se decidirá por el tribunal competente, que se guiará para resolverla, únicamente por lo que resulte más beneficioso para los menores.

En igualdad de condiciones, se atendrá, como regla general, a que los hijos queden al cuidado del padre en cuya compañía se hayan encontrado hasta el momento de producirse el desacuerdo; prefiriendo a la madre si se hallaban en compañía de ambos $\mathrm{y}$ salvo, en todo caso, que razones especiales aconsejen cualquier otra solución.

Como se expresa, una vez disuelto el vínculo matrimonial en la regulación vigente acerca de la posibilidad de formalizar prontamente un nuevo matrimonio, se ha evidenciado, sin dudas, a pesar de las diferencias biológicas o fisiológicas entre hombre y mujer, la intención del legislador de un tratamiento hasta donde es posible igualitario.

El tratamiento igualitario de ambos cónyuges es también evidente en las llamadas medidas definitivas relativas que se plasman en la sentencia de divorcio sobre guarda y cuidado de los hijos menores, en que nada cuenta si el hijo es hembra o varón, superándose el enfoque sexista del pasado (Ley de divorcio de 1934) que reservaba un destino marcado por su sexo a los hijos de cinco años en adelante, al establecer como régimen que el padre tendría la guarda de los hijos varones y la madre la de las hijas hembras.

Sin embargo, la normativa vigente del Código de Familia, establece reglas que colocan en el orden de prelación, primeramente a la convención que sobre el particular celebren los padres y de no mediar estas o ser atentatorias a los intereses materiales o morales de los hijos, a la decisión del Tribunal, el que se guardará para resolver la situación indefinida, únicamente por lo que resulte más beneficioso para los menores (artículo 89). Si hay igualdad de condiciones, se seguirá como regla que los hijos queden al cuidado 
del padre en cuya compañía se hayan encontrado hasta el momento de producirse el desacuerdo y es entonces que se preferiría a la madre, si es que los hijos se hallaban en compañía de ambos (artículo 89).

Se considera que el enfoque de género en este caso específico está revestido de determinismos tradicionalistas, biologicistas y sexistas, ya que la norma postula un fallo favorable a la madre cuando en realidad se debía orientar al tribunal decisor agotar todos los medios a su alcance para determinar quién tiene el mejor derecho, lo que evidencia que es esta una postura no ajustada al principio de equidad. Dicha disposición normativa, también se piensa atendiendo al rol de cuidadoras que socialmente ha sido otorgado a las mujeres, está basada en estereotipos o el prejuicio popularmente conocido de que "madre es una sola y padre es cualquiera". Esta es una concepción que está presente en la mentalidad no solo de quienes legislan, sino también en la de quienes llevan a cabo el ejercicio de aplicar la ley.

El niño o la niña debe estar donde mayores condiciones morales y materiales existan, ya sea con la madre o el padre y no debe mediar un criterio expresado en ley que preestablezca que debe ser con la madre, una regulación que cobra mayor fuerza en el tratamiento del tema por parte del tribunal y que sin dudas puede parcializar el proceso.

Se reconoce que en Cuba existen varios mecanismos para otorgar la guarda y cuidado con la mayor justicia posible a la madre o el padre que lo merezca, y que incluso uno de ellos es que en el tribunal de Familia existe un equipo multidisciplinario que escucha hasta el parecer del o la menor en conflicto, pero también reconoce que fallar a favor del padre llevaría una justificación más que fundada ante la propia familia y la sociedad, una cuestión que es considerada tradicionalmente inconcebible.

Nada patentiza o demuestra que una madre es mejor cuidadora que un padre, cuando la realidad evidencia que hay padres que están a la par o son mejores cuidadores que estas. Mientras se siga considerando que a la madre le corresponde ese derecho y al padre el de la educación a distancia de los hijos o hijas no se podrá encontrar la verdadera justicia, ni habrá cambio de mentalidad.

Se opina que en este caso en la interpretación y aplicación de la ley debe posesionarse a la madre y al padre en igualdad de condiciones sin que se favorezca a un sexo por encima del otro.

En el Derecho sobre Bienes, en las normativas cubanas de la vivienda -Ley No. 65, Ley General de la Vivienda de 23 de 
diciembre de 1988-, en lo relativo a los límites legales al derecho del propietario, en la Sección Primera "Derechos y obligaciones de los Propietarios" se plantea que:

Artículo 64. Los propietarios de las viviendas determinarán libremente qué personas convivirán con ellos y estarán facultados para dar por terminada la convivencia de cualquiera persona, para lo que no requerirán declaración administrativa ni judicial (...).

En correspondencia con lo expuesto se plantea:

Artículo 65. La facultad que concede al propietario el artículo precedente no podrá ejercerse contra:

Ascendientes y descendientes del propietario:

$\checkmark \quad$ Madre con uno o más hijos habidos en el matrimonio, formalizado o no, con el propietario siempre que ella tenga la guarda y cuidado de los hijos y no tuviere otro lugar de residencia;

$\checkmark \quad$ Madre con uno o más hijos menores que lleven tres o más años ocupando la vivienda y no tuvieren otro lugar de residencia;

Ancianos que lleven tres o más años ocupando la vivienda y no tuvieren otro lugar de residencia; $\checkmark$ Cualquier otro caso que a juicio de la autoridad competente constituya una manifiesta injusticia o acto inhumano.

De acuerdo a lo regulado en las disposiciones precedentes, el propietario puede ejercer el cese de convivencia contra todos los que habitan su morada excepto contra la madre de sus hijos, si no tuviere otro lugar de residencia; madre con hijos menores que lleven tres años o más en su vivienda, y que cumplan la condición anterior de no poseer otra residencia; además de ascendientes y descendientes del propietario, o casos de clara injusticia valorados por la autoridad.

En primer lugar, se considera a partir de otros análisis históricos desarrollados en la investigación, que dicha disposición normativa responde a un contexto históricosocial que mejoró significativamente la posición de la mujer, atendiendo a que la misma fue firmada a finales de la década de los 80, un período en el que se promulgó el Código de Trabajo (1984) y el Reglamento para la Política del Empleo (1987), como parte de las acciones revolucionarias para ofrecer garantías y oportunidades a las mujeres, completándose una legislación que ofrecía derechos en los planos personal, patrimonial, laboral, sexual, reproductivos y filiales, sobre todo en lo referente a la 
protección de la madre trabajadora (Silva \& Pérez, 2017a).

En segundo lugar, se opina como justa la regulación para la madre, partiendo de que responde a la necesidad de prestar especial protección no solo a esta (quien asumía el rol socialmente atribuido de cuidar a sus hijos) sino a los propios hijos menores habidos en el matrimonio o no, a fin de garantizarles un lugar seguro para sus vidas.

Como se evidencia en el artículo 65 la norma protege a la mujer madre de menores $\mathrm{y}$ lo hace sin necesidad de prueba y por formulación taxativa, prejuzgando en su favor cualquier fallo administrativo por decisión del legislador, sin embargo, al llevar a cabo un análisis del enfoque de género en la disposición, en el caso de que la situación fuera contraria y la propietaria fuera la mujer -con sus respectivos derechos declarados en el cuerpo de la norma-, el hombre padre de hijos menores casado con esta, estaría en una condición solo definible por decisión de la autoridad competente, y ante el supuesto de injusticia o acto inhumano, pues dicha regulación no establece garantía alguna para el sexo masculino.

Dicha norma es sexista y tradicionalista, está basada en el prejuicio que supone el ser hombre ante el ser mujer, dotado este de la fuerza del sexo masculino, socialmente reconocida, quien además siempre hallará una solución en circunstancias como estas y por otro lado la mujer tiene el peso mayor en la crianza y el cuidado de sus hijos. Se considera que en la práctica jurídica en estos casos debe considerarse también al padre a la hora de interpretar y aplicar la ley.

\section{Consideraciones finales}

La categoría género es esbozada por la teoría desde su incorporación al debate científico en la década de los años setenta hasta la actualidad, como la construcción social y/o cultural que en cada sociedad tiene su propuesta de modelos para los sexos y que pueden variar a través del tiempo, constituyendo un eje transversal en los estudios del ordenamiento jurídico cubano para la práctica jurídica actual a partir de su articulación con la perspectiva de la equidad; en tanto el enfoque de género en el ordenamiento jurídico cubano se regula con rango constitucional teniendo en cuenta la igualdad de derechos y deberes entre hombres y mujeres, aunque desde el Derecho Penal, el Derecho de Familia y el Derecho sobre Bienes se evidencian disposiciones inequitativas, basadas en patrones de discriminación que en ocasiones favorecen a la mujer o al hombre 
indistintamente, cuando debía existir un único tratamiento para ambos sexos.

A partir de ello, en presencia de estos casos en el Sistema de Tribunales Populares o la Fiscalía General de la República, se debe tener en cuenta el desarrollo científico obtenido en materia de género y los estudios avanzados sobre estos particulares en la actualidad, para que sin cambiar la norma analizada y respetando lo regulado en la ley se eliminen o disminuyan las brechas de inequidad que afectan a la sociedad; pues las disposiciones jurídicas en cuestión -que pertenecen a las décadas de los años setenta y ochenta-, responden a un contexto histórico social donde el progreso teórico de la categoría género era aún escaso y de pocos años de existencia. En la interpretación y posterior aplicación del Derecho Penal, el Derecho de Familia y el Derecho sobre Bienes en la práctica jurídica, debe ejercitarse la perspectiva de la equidad. En los delitos de Violación y Pederastia con Violencia debe asumirse que la integridad sexual de la mujer y la del hombre poseen el mismo valor y por tanto deben tener el mismo marco sancionador. En los casos de guarda y cuidado de hijos e hijas menores de edad, debe posesionarse a la madre y al padre en igualdad de condiciones sin que se favorezca a un sexo por encima del otro, y en cuanto a la aplicación de las disposiciones relativas a los límites legales del derecho del propietario a declarar el cese de convivencia de quienes habitan su morada, debe protegerse también al padre de hijos e hijas cuando no sea este el propietario de la vivienda $\mathrm{y}$ no tuviere otro lugar de residencia.

A partir del estudio desarrollado se entiende además que existe una estrecha relación entre la triada género - desarrollo social - Derecho, atendiendo a que este último se considera esencialmente interdisciplinario y vinculado al desarrollo social, del cual se derivan aspectos teóricos centrales como las políticas sociales y la equidad, con una marcada influencia en el progreso de todas las dimensiones de la vida humana: políticas, económicas, sociales, culturales, materiales, morales e intelectuales y jurídicas, esta última como base esencial para lograr el mencionado desarrollo en cada dimensión citada; ello presupone el aumento de la calidad de vida del ser humano y la satisfacción de sus necesidades básicas -como ser social-, lo que pudiera traducirse en el acceso a la igualdad, la justicia, la equidad de la leyes que rigen su actuar.

Considerar el análisis desarrollado en las ramas del Derecho expuestas, permitirá a jueces y fiscales en Cuba en el ejercicio de 
su profesión -en la interpretación de la ley ante los casos de guarda y cuidado de los hijos o en lo referente a los límites legales del derecho del propietario a declarar el cese de convivencia contra quienes habitan su morada-, aplicar la ley equitativamente, de forma tal que se contribuya a la disminución de las desigualdades para ambos sexos, lo que posibilitará el desarrollo social en tanto se llevará a cabo el ejercicio de la justicia, un componente esencial para el progreso de la sociedad. De esta forma se cumplirá con el Principio de Igualdad establecido en la Constitución de la República de Cuba de 1976.

\section{Referencias bibliográfica}

Ahr, I. (2007). Género y Educación. Cuaderno temático. Perú: Ed. EBRA E.I.R.L.

Andrés-Pueyo, A. (1996). Manual de psicología diferencial. Madrid: Mc GrawHill Interamericana de España, S.A. Disponible en: http://booksmedicos.me/manual-depsicologia-diferencial-antonio-mandrespueyo/

Anteproyecto de Código de Familia de 2008. Publicado en Colección Jurídica del
Tribunal Popular Provincial de Pinar del Río, Cuba. [citado 2 ene 2017]. Material

Digital.

Camargo, J. (1999). Género e Investigación Social. Curso de Formación en Género. Módulo 2. Instituto de la Mujer de la Universidad de Panamá/ UNICEF: Editora Sibauste, Primera edición.

Caram, T. (2016). Oportunidades y posibilidades para el empoderamiento. Revista Estudios del Desarrollo Social: Cuba y América Latina, 4 (4), Número Extraordinario, 176-189. Disponible en: http://www.revflacso.uh.cu/index.php/EDS /article/view/147

Ley No. 62. Código Penal de Cuba de 1987.Publicada en Colección Jurídica. Ministerio de Justicia. La Habana, Cuba.

Colectivo de Autores (2006). Manual de Derecho Romano. La Habana: Editorial Félix Varela.

Constitución de la República de Cuba de 1976 (actualizada con la Reforma de 1992). Publicada en Colección de textos legales en septiembre de 2009. La Habana, Cuba: Ediciones ONBC. 
Chiarotti, N. (1995). Primera Conferencia

Mundial sobre la Mujer, México 1975.

Disponible en: $\quad$ http://base.d-p-

h.info/es/fiches/premierdph/fiche-

premierdph-2359.html

Declaración Universal de los Derechos Humanos de 1948. Publicada en Pino, C.E. (2016). Selección de Instrumentos Jurídicos Internacionales. Tomo 3, La Habana: Editorial Universitaria Félix Varela.

Decreto-Ley 781 de 1934. Publicado en Pichardo, O. (1980): Documentos para la Historia de Cuba. (pp. 527-528), Tomo IV. Primera parte. Ciudad de la Habana: Editorial de Ciencias Sociales.

Diccionario de la Lengua Española, Edición del Tricentenario (2014).Palabras equidad; desarrollo, desarrollar. [Internet]. [citado 7 jul 2017]. Disponible en: http://dle.rae.es/?id=UFbxsxz

Diccionario de la Lengua Española El Mundo.es. (2017)[Internet]. [citado 1 oct 2017]. Disponible en: http://www.elmundo.es/diccionarios/

Fernández, L. et al. (2003). Género y subjetividad. En Pensar en la Personalidad. La Habana: Editorial Félix Varela.
Fleitas, R. (2000). Identidad femenina y maternidad adolescente. Tesis de doctorado. Universidad de La Habana. Cuba. Disponible en: http://tesis.repo.sld.cu/531/

Informe de la Cuarta Conferencia Mundial sobre la Mujer, Beijing, 1995. Naciones Unidas. Disponible en:http://www.un.org/womenwatch/daw/be ijing/pdf/Beijing\%20full\%20report\%20S.p df

Lagarde, M. (2008). La multidimensionalidad de la categoría género y del feminismo. En Género, selección de lecturas. Compilación. La Habana: Editorial Caminos.

Lagunas, M., Beltrán, L.F. \& Ortega, A. (2016). Desarrollo, feminismo y género: cinco teorías y una canción desesperada desde el Sur. Revista Estudios del Desarrollo Social: Cuba y América Latina. Vol. 4, No. 2, mayo-agosto, 62-75. Disponible en: http://scielo.sld.cu/scielo.php?script=sci_ar ttext\&pid=S2308-01322016000200006

Ley 1289. Código de Familia de Cuba.Publicada enColección de textos 
legalesen septiembre de 2015. La Habana, Cuba: Ediciones ONBC.

Ley No. 65. Ley General de la Vivienda. Publicada en Colección de textos legalesen septiembre de 2015. La Habana, Cuba: Ediciones ONBC.

López, L. (2011). La teoría de género y sus heterogéneas perspectivas, un reclamo pertinente. Revista Contribuciones a las Ciencias Sociales, No. de noviembre 2011. Disponible en: http://www.eumed.net/rev/cccss/15/1ls.htm 1

Madoo, P. \& Niebrugge-Brantley, H. (2008a). Teoría Feminista Contemporánea. En Ritzer, G. (2008). Teoría Sociológica Contemporánea. Primera y segundaparte. La Habana: Editorial Félix Varela.

Madoo, P.\& Niebrugge-Brantley, $H$. (2008b). La multidimensionalidad de la categoría género y del feminismo. En Género, selección de lecturas. Compilación. La Habana: Editorial Caminos.

Maceo, A. (2012). Un acercamiento desde la Sociología del Género al comportamiento reproductivo de la población en el municipio Santiago de Cuba. Revista Caribeña de Ciencias Sociales, diciembre 2012, en http://caribeña.eumed.net/unacercamiento-desde-la-sociologia-delgenero-al-comportamiento-reproductivode-la-poblacion-en-el-municipio-santiagode-cuba/

Matilla, A (s/f). Introducción al Derecho. Holguín: Centro Gráfico de Reproducciones para el Turismo.

Maurizio, R. (2010). Enfoque de género en las instituciones laborales y las políticas del mercado de trabajo en América Latina. División de Desarrollo Económico de la Comisión Económica para América Latina y el Caribe (CEPAL). Publicación de las Naciones Unidas. Disponible en: http://archivo.cepal.org/pdfs/2010/S10003 13.pdf

Miranda \& Peña (2001). Relaciones de Género con Equidad: Guía conceptual y metodológica. Editorial IICA-Holanda.

Molina Díaz, E. (2011). La universidad por un nuevo saber ambiental hacia la sostenibilidad. Cuadernos de Educación y Desarrollo, 3 (31), 16. 
Pautassi, L. (2012). La igualdad en espera: el enfoque de género. Lecciones y Ensayos, Número 89.

Programa de la Maestría en Desarrollo Social (2015). Documento impreso. Facultad de Ciencias Sociales y Humanísticas. Universidad Hermanos Saíz Montes de Oca de Pinar del Río, Cuba.

Proveyer, C. (2005). Selección de lecturas de Sociología y Política Social de Género. La Habana: Editorial Félix Varela.

Rega, E. E. (2003). Delitos contra el normal desarrollo de las relaciones sexuales y contra la familia, la infancia y la juventud. En Derecho Penal Especial, tomo II. La Habana: Editorial Félix Varela.

Rodríguez, Y. \& Páez, M. (2016). Desarrollo social y política de empleo a propósito del Código de Trabajo cubano. Revista Estudios del Desarrollo Social: Cuba y América Latina. Vol. 4, No. 3. Recuperado de: http://ojs.uh.cu/DesarrolloSocial/index.php $\underline{\text { EDS }}$

Rojas, G. (2012). Perspectiva social del Derecho de Familia en Cuba. Recuperado de: https://www.gestiopolis.com/perspectiva-

$\underline{\text { social-derecho-familia-cuba/ }}$

Sanchis, C. \& Suárez, L. (2017). Género y mediación familiar en Cuba: posibilidades y análisis a la luz del ordenamiento español. Revista Boliviana de Derecho, $\mathrm{N}^{\mathrm{o}} 24$, julio 2017, ISSN: 2070-8157, pp. 320349.Disponible

en: http://artículo\%20de\%20violencia\%20de\% 20género.pdf

Scott, J. (1990). El género: una categoría útil para el análisis histórico. Recuperado de http://www.cholonautas.edu.pe/modulo/upl oad/scott.pdf

Staff, M. (2000). Género y Derecho. Curso de Formación en Género. Módulo 3. Instituto de la Mujer de la Universidad de Panamá. Primera edición. Legalinfo, Panamá: Editora Sibauste. Tomado de: http://www.legalinfopanama.com/articulos larticulos_21f.htm

Silva, J. L. \& Pérez, A. (2017a). El enfoque de género en la evolución del ordenamiento jurídico cubano y su manifestación en el Derecho Penal actual. Revista Estudios del Desarrollo Social: Cuba y América Latina. Vol. 5, No. 2, 1-11. Disponible en: 
http://ojs.uh.cu/DesarrolloSocial/index.php $\underline{\text { EDS }}$

Silva, J.L. \& Pérez, A. (2017b). El enfoque de género en el Derecho sobre bienes inmobiliarios en Cuba. Revista Santiago. No.144, septiembre-diciembre, 492-506 Disponible en:

http://revistas.uo.edu.cu/index.php/stgo/iss $\underline{\text { ue/view/200 }}$

Silva, J.L., Pérez, A. \& Páez, L.D. (2017). La formación del profesional desde el enfoque de género en el Derecho Penal cubano. Revista de Educación y Derecho. No. 16, septiembre de 2017. Disponible en: http://revistes.ub.edu/index.php/RED/index

Silva, J. L. \& Pérez, A. (2018). El enfoque de género en el vigente Código de Familia cubano. Revista Estudios del Desarrollo Social: Cuba y América Latina.Vol. 6, No. 1, enero-abril, 28-42. Disponible en http://ojs.uh.cu/DesarrolloSocial/index.php /EDS

Stoller R. (1994). Sex and Gender: On the

Development of Masculinity and

Femininity, Science House, New York

City. p. 383.Disponible en

http://us.karnacbooks.com/product/sex- and-gender-the-development-of-

$\underline{\text { masculinity-and-femininity/22/ }}$

Trujillo, I. \& Hernández, C.N. (2008). La multidimensionalidad de la categoría género y del feminismo. En Género, selección de lecturas. Compilación. La Habana: Editorial Caminos.

Valdebenito, E. (2002). Género y Desarrollo (algunas reflexiones y un glosario práctico para facilitar el trabajo a nivel local). Programa DelNet GenderEquality- Centro Internacional de Formación de la OIT. Recuperado de: http://www.itcilo.it/delnet

Vasallo, N. (2004). El género: un análisis de la "naturalización" de las desigualdades. En Colectivo de autores. Heterogeneidad social en la Cuba actual Centros de Estudio y Bienestar Humano. Universidad de La Habana. Cuba.

Varela, N. (2013). Feminismo para principiantes. España: Ediciones B.

Villabella, C. M. (2012): Metodología de la investigación sociojurídica. Libro digital. Facultad de Derecho. Universidad de La Habana, Cuba. 
Periódico do Núcleo de Estudos e Pesquisas sobre Gênero e Direito Centro de Ciências Jurídicas - Universidade Federal da Paraíba V. 7 - No 02 - Ano 2018 ISSN | 2179-7137 | http://periodicos.ufpb.br/ojs2/index.php/ged/index

Zona Económica (2015). Retrieved March

18, 2015, from

www.zonaeconomica.com/concepto-

desarrollo 